\title{
natureINSIGHT CHEMISTRY AND ENERGY
}

16 August 2012 / Vol 488 / Issue No 7411

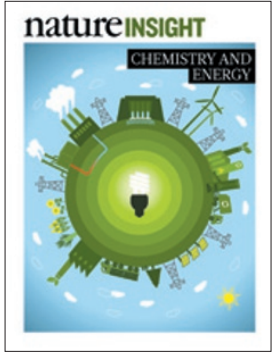

Cover illustration:

S. S. Moran/

iStockphoto

\section{Editor, Nature}

Philip Campbell

Publishing

Nick Campbell

Claudia Deasy

Insights Editor

Karl Ziemelis

Production Editor

Jenny Rooke

Art Editor

Nik Spencer

Sponsorship

Reya Silao

Yvette Smith

Gerard Preston

Production

Emilia Orviss

Marketing

Elena Woodstock

Hannah Phipps

Editorial Assistant

Rina Nozawa

The Macmillan Building

4 Crinan Street

London N1 9XW, UK

Tel: +44 (0) 2078334000

e: nature@nature.com

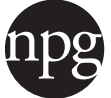

nature publishing group
$\mathrm{L}$ ife, as many people know it, would not be possible without access to cheap and abundant energy. More than $85 \%$ of the world's energy comes from the combustion of oil, coal and natural gas. Scientists generally agree that the combustion of fossil fuels is causing warming of Earth's climate and having deleterious effects on the environment. Many fear that climate change will lead to coastal flooding, an increase in the prevalence of vector- and water-borne infectious diseases, and conflict over fossil fuels, water and food. Clearly, action is needed.

Reducing our consumption of energy and adopting a more frugal lifestyle could be the first steps, but they cannot be the only strategies. The fossil fuels that remain must be used more effectively and other energy sources need to be identified, preferably ones that are climate neutral. The Reviews in this Insight cover a small fraction of the various scientific and engineering endeavours that may eventually deliver the technological innovations to harvest energy from alternative sources.

The Reviews clearly show that there are many energy solutions to be explored. These possible strategies range from the well-established photovoltaics to nascent methods, such as the use of algae to produce potential fuels. However, we still have a long way to go before approaches such as those covered in this Insight can compete in earnest with conventional energy sources. We hope that the articles that appear in the following pages will inspire young scientists and engineers to join the quest to secure a sustainableenergy future.

We are pleased to acknowledge the support of TOTAL in producing this Insight. As always, Nature carries sole responsibility for all editorial content and peer review.

\section{Rosamund Daw, Joshua Finkelstein \& Magdalena Helmer Senior Editors}

\section{CONTENTS}

\section{PERSPECTIVE}

294 Opportunities and challenges for a sustainable energy future Steven Chu \& Arun Majumdar

\section{REVIEWS}

304 Materials interface engineering for solution-processed photovoltaics Michael Graetzel, René A. J. Janssen, David B. Mitzi \& Edward H. Sargent

313 Membrane-based processes for sustainable power generation using water Bruce E. Logan \& Menachem Elimelech

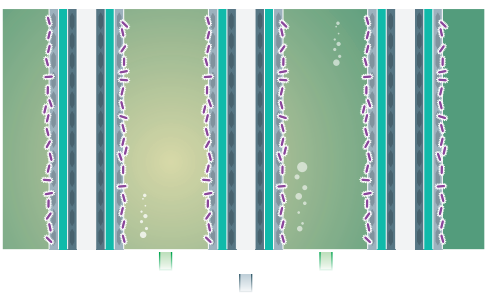

320 Microbial engineering for the production of advanced biofuels Pamela P. Peralta-Yahya, Fuzhong Zhang, Stephen B. del Cardayre \& Jay D. Keasling

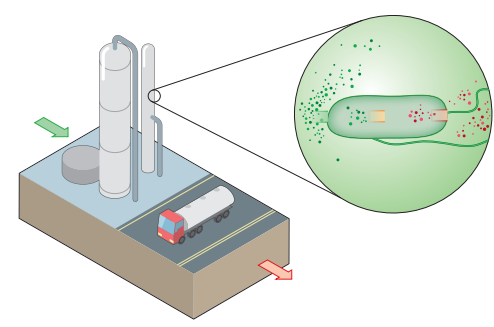

329 Exploiting diversity and synthetic biology for the production of algal biofuels D. Ryan Georgianna \& Stephen P. Mayfield

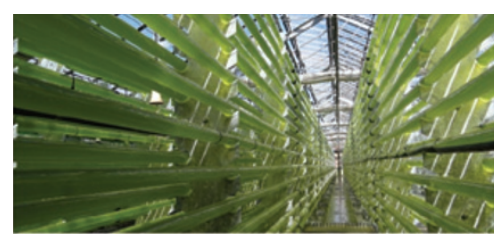

